\title{
BLOCO AFRO ILÊE-AIYÊ: UMA HISTÓRIA DE LUTA ANTIRRACISTA
}

\author{
Juliana Araujo de Paula ${ }^{1}$ \\ Recebido em: 13/11/2020 \\ Aprovado em: 16/12/2020
}

\begin{abstract}
Resumo: O presente trabalho tem como objetivo apresentar reflexões sobre a história do Bloco Afro "Ilê Aiyê" e seus impactos sociais. Trata-se de um bloco de carnaval que foi fundado em 1974 na cidade de Salvador/Bahia que transborda suas realizações para além dessa festa e que tem forte papel social na luta pela igualdade racial. O processo de constituição do bloco, suas práticas educativas (Banda Erê, Escola Mãe Hilda e Projeto de Extensão Pedagógica), artísticas (Banda Aiyê) e a Noite da Beleza Negra revelam importantes aspectos de sua história. A revisão de literatura de teses e dissertações sobre esse contexto indicam que as características do bloco, suas práticas cotidianas de produção, divulgação, compartilhamento e fortalecimento da cultura afro-brasileira e, especialmente, de empoderamento da mulher negra, apresentam-se como tempos/espaços de ações de luta antirracista. A eleição da Deusa do Ébano na Noite da Beleza Negra é um importante exemplo dessa função social desempenhada pelo bloco. Além disso, geram impactos na comunidade em que o bloco está inserido e, de forma mais ampliada, nacionalmente uma vez que o Ilê Aiyê influenciou e influencia diversas ações antirracistas no país.
\end{abstract}

Palavras-chave: Blocos Afro; Carnaval; Cultura afro-brasileira; Luta Antirracista; Mulher Negra.

\section{GRUPO AFRO ILÊ-AIYÊ: UNA HISTORIA DE LUCHA ANTIRACISTA}

Resumen: Este artículo tiene como objetivo presentar reflexiones sobre la historia del grupo afro "Ilê Aiyê" y sus impactos sociales. Es una organización carnavalera que se fundó en 1974 en la ciudad de Salvador / Bahía que desborda sus logros más allá de esta fiesta y que tiene un fuerte rol social en la lucha por la igualdad racial. El proceso de constitución del grupo, sus prácticas educativas (Banda Erê, Colegio Mãe Hilda e Projecto de Extensión Pedagógica), artísticas (Banda Aiyê) y la Noche de la Belleza Negra revelan aspectos importantes de su historia. La revisión de la literatura de tesis y disertaciones sobre este contexto indica que las características del grupo, sus prácticas cotidianas de producción, difusión, puesta en común y fortalecimiento de la cultura afrobrasileña y, especialmente, el empoderamiento de las mujeres negras, se presentan como tiempos / espacios para acciones de lucha antirracista. La elección de la Diosa de Ébano en la Noche de la Belleza Negra es un ejemplo importante de esta función

\footnotetext{
1 Licenciada em Educação Física (UFMG), Mestre em Educação (FAE/UFMG) e Doutoranda do Programa de Pós Graduação Interdisciplinar em Estudos do Lazer (EEFFTO/UFMG). Professora da Rede Municipal de Educação de Belo Horizonte (RME/PBH). ORCID: https://orcid.org/0000-0003-4247-8355. E-mail: j.araujodepaula@gmail.com.
} 
social que realiza el grupo.Además, generan impactos en la comunidad en la que se inserta el grupo y, más ampliamente, a nivel nacional ya que Ilê Aiyê influyó e influye en varias acciones antirracistas en el país.

Palabras clave: Grupos Afro; Carnaval; Cultura afrobrasileña; Lucha Antirracista; Mujer Negra.

\section{AFRO ILÊ-AIYÊ GROUP: A HISTORY OF ANTI-RACIST STRUGGLE}

Abstract: This paper aims to present reflections on the history of the Afro Group "Ilê Aiyê" and its social impacts. It's a carnival block that was founded in 1974 in the city of Salvador / Bahia that overflows its achievements beyond this party and that has a strong social role in the fight for racial equality. The group constitution process, its educational practices, (Banda Erê, Mãe Hilda' School and pedagogical extension project), artistic (Banda Aiyê) and the "A Noite da Beleza Negra" reveals important aspects of its history. The literature review of theses and dissertations on this context indicates that the characteristics of the group, its daily practices of production, dissemination and strengthening of Afro-Brazilian culture and, especially, the empowerment of black women, are presented as times as an anti-racist actions. The election of the Ebony Goddess in the Night of Black Beauty is an important example of this social function performed by the grupo. In addition, they generate impacts on the community in which the group is inserted and, more broadly, nationally since Ilê Aiyê influenced and influences several anti-racist actions in the country.

Keywords: Afro groups; Carnival; Afro-Brazilian culture; Anti-racist practice; Black woman.

\section{Introdução}

Neste texto destacam-se os principais apontamentos de uma pesquisa inicial cujo objetivo foi realizar um levantamento bibliográfico da produção teórica sobre o Bloco Afro Ilê Aiyê a fim de analisar seu percurso de constituição. Trata-se de um bloco de carnaval que, desde sua origem, transborda suas realizações para além dessa festa e que tem forte papel social na luta pela igualdade racial. A partir de uma busca na Biblioteca Digital Brasileira de Teses e Dissertações (BDTD) e no Repositório de Teses e Dissertações da Universidade Federal da Bahia foram selecionados trabalhos que tematizaram o Ilê Aiyê e, a partir de diferentes olhares, contaram sua história.

A pesquisa adotou como pressuposto o entendimento de que Ilê Aiyê, ao longo de quatro décadas, consolidou-se como uma das principais associações do Brasil que tem como tarefa a luta contra a desvalorização do negro. Situado em Salvador, a cidade com a maior população de negros fora de África ${ }^{2}$, o surgimento do Ilê Aiyê teve papel importante para o renascimento

\footnotetext{
${ }^{2}$ De acordo com os dados do Instituto Brasileiro de Geografia e Estatística (IBGE), em 2017, em Salvador 8 em cada 10 moradores eram negros.
} 
de afoxés ${ }^{3}$ e criação de outros blocos afros nos anos 70. Nessa década, o carnaval baiano teve sua força política e cultural potencializada a partir da ação de protestos desses blocos e afoxés ao denunciarem e explicitarem a assimétrica relação sócio racial do país. (RISÉRIO, 1995).

Como afirma Almeida (2010, p.64), "seu principal papel é mudar mentalidades e negociar politicamente outro lugar no mundo para o homem de cor, destacando outro senso estético". Trata-se, portanto, de um bloco de carnaval que promove realizações para além dessa festa, que tem forte papel social na luta pela igualdade racial. "O Ilê não mais se resume a um bloco, em que pese este ser considerado seu maior produto de expressão cultural. O Ilê, atualmente, se compreende como uma entidade, uma instituição, que preserva a cultura negra por múltiplos recortes (...)” (FERREIRA, 2009, p.95). Compreender a história dessa instituição é, portanto, uma forma de revelar tempos e espaços de re-existência da população negra.

Para isso, foi utilizado o método de pesquisa bibliográfica para levantar os dados e, posteriormente, realizar a análise. Por meio de uma pesquisa na Biblioteca Digital Brasileira de Teses e Dissertações (BDTD) e no Repositório de Teses e Dissertações da Universidade Federal da Bahia foram identificadas teses e as dissertações de diferentes áreas de conhecimento que tematizaram a instituição e que, por isso, revelam faces de sua história. A pesquisa culminou no levantamento de treze trabalhos, sendo oito dissertações e cinco teses (FREITAS, 1995; SILVA, 2001; SOUZA, 2007; SILVA FCC, 2008; SILVA CAC, 2008; FERREIRA, 2009; ALMEIDA, 2010; MOREIRA, 2013; OLIVEIRA, 2016; MERCÊS, 2017; MARTINS, 2017; SANTANA, 2018; ARAUJO, 2020). Após esse processo, iniciou-se a análise dos trabalhos a fim de desenvolver reflexões sobre a constituição do Bloco Afro Ilê Aiyê.

\title{
Que Bloco é esse? O início da trajetória
}

\author{
Somo crioulo doido, somos bem legal \\ Temos cabelo duro, somos black power \\ Somo crioulo doido, somos bem legal \\ Temos cabelo duro, somos black power \\ Que bloco é esse? Eu quero saber \\ É o mundo negro que viemos mostrar pra você (pra você) \\ Que bloco é esse? Eu quero saber \\ É o mundo negro que viemos mostrar pra você (pra você) \\ Branco, se você soubesse o valor que o preto tem \\ Tu tomavas banho de piche pra ficar negrão também \\ E não te ensino a minha malandragem \\ Nem tão pouco minha filosofia, não? \\ Quem dá luz a cego é Bengala Branca e Santa Luzia
}

\footnotetext{
${ }^{3}$ Os afoxés são agremiações carnavalescas que tem uma ligação direta aos terreiros de candomblé. Sua saída no carnaval compõe parte do ritual dessa religião.
} 
(Música Que bloco é esse - Paulinho Camafeu)

Embalados por esses versos e os toques percussivos, nasceu em 1974 o Ilê Aiyê, bloco afro que fez seu primeiro desfile em 1975. Foi criado por um grupo de jovens do bairro da Liberdade em Salvador que tinham influência de importantes intelectuais ligados ao Movimento Negro Americano e as questões culturais e políticas de África (ALMEIDA, 2010 e FREITAS, 1995). Em plena ditadura civil militar brasileira, o Ilê surgiu na cena carnavalesca soteropolitana com o objetivo de valorizar e divulgar a cultura afro brasileira através da afirmação da beleza da estética negra.

O primeiro desfile do Ilê Aiyê, realizado no carnaval de 1975, concentrou-se em elementos que remetiam diretamente a matriz africana. Sejam as músicas, roupas, nomes, penteados e temas, tudo no desfile do bloco da Liberdade tinha como referencial a história negra. (MARTINS, 2017 p.239)

As cores do Ilê são importantes marcas da sua estética. Branco, vermelho, amarelo-ouro e preto compõem as fantasias que os associados usam a cada carnaval.

Associadas aos seus valores espirituais e históricos: o branco é a paz, o valor absoluto. $\mathrm{O}$ vermelho rubro é uma homenagem à memória dos que lutaram pela libertação, é o sangue derramado. $\mathrm{O}$ amarelo-ouro representa a riqueza cultural e a beleza dos povos negros. O negro é a cor da pele (ILÊ AIYÊ, 2014; p. 221)

Os tecidos dos trajes são também uma importante característica do Ilê Aiyê. Eles são produzidos especialmente a cada ano e carregam pinturas relacionadas ao tema escolhido.

A pintura dos tecidos se deu de forma artesanal até o carnaval de 1986. A partir do ano seguinte a produção passou a ser industrial, porém acarretou na diminuição do tempo parta a costura das indumentárias, pois geralmente o tecido tem chegado nas duas semanas que antecedem o carnaval, exigindo um trabalho acelerado da equipe de costura. Durante os preparativos para o carnaval o bloco conta com uma equipe de cerca de 30 costureiras para confecção das fantasias. (FREITAS, 1995, p.71)

O primeiro e segundo desfile não tiveram temas, mas a partir do terceiro, em 1977, o Ilê passou a desfilar sempre homenageando um país ou aspecto da cultura africana. (FERREIRA, 2009). O próprio nome do bloco já carrega em si a referência a África. De origem iorubá, o nome significa Casa de Negro. Segundo Araujo (2020), o nome foi escolhido após uma consulta pública realizada por Vovô, apelido pelo qual é conhecido Antônio Carlos dos Santos, um de dos fundadores do Ilê Aiyê. A africanidade, é, portanto, marca do Ilê nos mais diferentes aspectos.

Com suas músicas poesias, performances e estética o bloco considera uma pluralidade de códigos e linguagens (histórica, mítica, oral, religiosa, étnica, vivencial) que corroboram para a construção de uma identidade reflexiva onde 
o folião consegue orgulhar-se de ser negro. O Ilê auxilia na autoafirmação dos negros em uma sociedade que nega e discrimina as vivências e as produções culturais e intelectuais negras. (MERCÊS, 2017,p.79)

O Ilê Aiyê tem seu nascimento e o desenvolvimento de suas ações em estreito diálogo com o candomblé. "É preciso confirmar a existência do Ilê Aiyê como herança do terreiro Ilê Axé Jitolu, pois a permissão para a criação do "mundo negro", a casa do Ilê, foi dado pela Yalorixá Mãe Hilda Jitolu” (MOREIRA, 2013 , p.35). Os filhos carnais da Mãe Hilda foram, junto com amigos, responsáveis pela criação do bloco e, até hoje, compõem a diretoria da instituição. "Eu não sou negro novo, não descobri que era negro na rua, por acaso e sim por ter consciência de que era negro desde pequeno [...] essa orientação em casa e também por ter nascido em Terreiro de Candomblé. Outro ponto interessante é que eu sou de um bairro de maioria negra." (ANTÔNIO CARLOS DOS S. VOVÔ em depoimento à FREITAS, 1995, p.43)

Como definido pelo historiador Luiz Antônio Simas (2020) ${ }^{4}$, o candomblé configura-se como um "sistema de mundo" redefinido na diáspora, o que amplia seu entendimento para além de uma religião. Fundamentado em saberes vindos de África, essa "cultura da diáspora" firmase como território de resistência ao perpetuar conhecimentos, visões de mundo e uma filosofia própria que escapam da lógica eurocêntrica. As referências a esse modo de conhecer e estar no mundo são presentes nas diferentes práticas do bloco e o terreiro Ilê Axé Jitolu participa ativamente delas 5 .

O Ilê Aiyê inaugura, portanto, um movimento ao levar para as ruas do carnaval de Salvador toda uma estética negra para afirmação da beleza do negro e, a partir de uma ação artística e cultural, travar uma luta antirracista. Entretanto, é importante destacar que mesmo sendo um marco, talvez seja mais pertinente como defende Silva Cac (2018) dizer de uma retomada afirmativa "uma vez que o Ilê Aiyê não guardava a tão decantada primazia na construção da trama identitária, se levarmos em consideração a presença da cultura afro nas ruas da cidade do Salvador, ainda na virada do século XIX para o XX.” (SILVA CAC, 2018, p.47)

\section{A constituição de ações educativas}

\footnotetext{
${ }^{4}$ Discussão apresentada em diálogo com o Babalorixá Dário de Ossain transmitido na perfil do Instagram do Ilê $\begin{array}{lllllll}\text { Axé } & \text { Onixêgum } & \text { no } & \text { dia } & 08 / 07 / 2020 . & \text { Disponível } & \text { em }\end{array}$ https://www.instagram.com/tv/CCZmEHOJ_U4/?igshid=112sph6yeicp7

${ }^{5}$ Cabe ressaltar, a título de exemplificação, o ritual que antecede a saída do bloco de carnaval e é conduzido pela Ialorixá Mãe Hildelice Benta, que sucedeu a Mãe Hilda do Jitolu no comando da casa quando de seu falecimento.
} 
Fundado como bloco afro em 1974, foi no ano de 1986 que o Ilê se assumiu como associação cultural. (MOREIRA, 2013). O bloco passa assim a consolidar suas ações para além do carnaval. Em 1988 é criado um dos seus projetos de maior repercussão e impacto social, a Escola Mãe Hilda.

A princípio o projeto nasceu com cinco crianças, porém, rapidamente ganhou fama e reconhecimento da comunidade, logo mães e pais passaram a bater à porta do terreiro Ilê Axé Jitolú à procura de Mãe Hilda para inscreverem seus filhos. (...) Neste primeiro momento, as atividades eram oferecidas dentro do próprio terreiro, onde esteve até 2003, e com a inauguração da Senzala do Barro Preto, foram para lá transferidas. (ARAUJO, 2020, p.115)

A Escola no decorrer do tempo passou a ampliar os atendimentos e a transformar-se em uma instituição de ensino formal que atende anualmente cerca de 200 crianças da comunidade e dos bairros vizinhos. "Além de oferecer aulas das disciplinas da educação escolar tradicional como: português, matemática e geografia fazem parte do currículo pedagógico da escola a história social e cultura afro-brasileira, indo desde as crenças religiosas até a culinária e estética negra." (OLIVEIRA, 2016 p.109). Esse contexto educativo, portanto, desconstrói formas de educação racistas e colonizadas. Através de suas práticas, promove um modo outro de educar as crianças pautada na afirmação da identidade negra.

foi preciso construir outros pilares educativos, outras formas de educar e ser educado, distintas das práticas pedagógicas não críticas que historicamente segregaram saberes e fazeres de origem africana e afro-brasileira. O Ilê Aiyê se destaca neste campo, inovando com seus instrumentos sistemáticos e dinâmicos. Chamo de sistemáticos os Cadernos de Educação do Projeto de Extensão Pedagógica e, de dinâmico, o modo de educar as crianças na escola Mãe Hilda e Escola Banda Erê. A produção de materiais didáticos próprios, a integralização do saber na corporalidade e na prática dançante, lúdica e da poesia são exemplos de concretude aprendente e divergente, vivenciados na escola Mãe Hilda e na Banda Erê (MOREIRA, 2013, p.11)

Além da Escola Mãe Hilda, o Ilê desenvolve outras duas experiências educativas. O Projeto Band'erê iniciado em 1992 e que oferece formação artística baseada na cultura negra no contra turno escolar é um deles. "O processo de inserção, especialização e aprimoramento de crianças e jovens na arte da música é um dos principais frutos colhidos pelo projeto, além disso, em grande medida são pessoas oriundas do bairro do Curuzu e da Liberdade que por ali se formam" (ARAUJO, 2020, p.116).

A Escola Profissionalizante, que iniciou suas ações em 1997, que oferece cursos de capacitação para jovens é também um projeto educativo do Ilê que promove inclusão social. "A escola profissionalizante exige como pré-requisito básico o jovem ter entre 17 a 21 anos. Além disso, deve estar cursando a $7^{a}$ série ou já ter concluído o ciclo básico do ensino fundamental 
II. Os candidatos são submetidos a uma prova e a uma entrevista que selecionam os jovens." (MERCÊS, 2017, p.68). A partir de diferentes ações culturais, educativas e políticas, o Ilê Aiyê se consolidou como importante referência da luta antirracista. As ações essencialmente educativas parecem ser, nesse contexto, diferenciadas e inovadoras.

Para estes núcleos (Banda Aiyê, Banda Erê, Escola Mãe Hilda e Projeto de Extensão Pedagógica), os objetivos desta dinâmica cotidiana são a busca de uma educação integral de corpo, cunhada na transversalidade de problemas contemporâneos como drogas, sexualidade, doenças sexualmente transmissíveis e alimentação e a disposição destas pessoas com o meio em que vivem no sentido do espaço compartilhado. Perceber o sentido da etnicidade e a busca da diferenciação das culturas do corpo são outros objetivos. (MOREIRA, 2013, p. 84)

O corpo em movimento, ou melhor, o corpo dançante é possivelmente uma das grandes marcas dessa instituição. Não só no desfile do carnaval quando, em cortejo, uma multidão dança aos sons dos seus tambores. Nas atividades essencialmente pedagógicas a dança é parte dos percursos formativos (MOREIRA, 2013). As apresentações da Band’Aiyê, a banda musical ligada ao bloco que faz apresentações artísticas no decorrer do ano, são sempre acompanhadas por um corpo de dançarinas e dançarinos ${ }^{6}$. De acordo com a descrição no site oficial do Ilê Aiyê, "a dança afro é uma das características fundamentais do Ilê Aiyê."7

A centralidade corporal nos atos educativos do Ilê no sentido de corpo todo e aprendente, lúdico, expresso em várias linguagens como a poesia e a dança. Estas formas de educar estão impregnadas no corpo dos formadores e dos que são formados no Ilê Aiyê, configurando-se assim como uma educação estética (MOREIRA, 2013, p.46)

Essa centralidade do corpo, além das práticas pedagógicas, é expressa no cotidiano do Ilê, nas suas muitas ações. O corpo é, portanto, presença e potência na luta travada cotidianamente por essa instituição. "E os corpos estão tanto no centro das lutas como as lutas estão no centro dos corpos. Os corpos são corpos performativos e assim, através do que fazem, renegociam e ampliam ou subvertem a realidade existente" (SANTOS, 2019, p. 138). Ao se pensar esse corpo racializado, essa relação com a luta ganha uma proximidade ainda maior. $\mathrm{O}$ corpo que carrega a dor e a opressão, mas que na mesma proporção, também carrega a ancestralidade e a possibilidade de resistir.

\footnotetext{
${ }^{6}$ Exemplo dessa importância foi a live realizada no dia 12/07/2020 pelo Ilê Aiyê que contou com a participação de dançarinas. No período da pandemia do COVID-19 nesse mesmo ano, muitos artistas realizaram transmissões via internet de suas apresentações, mas é importante notar que a presença de dançarinos não era habitual. Mesmo com as formações completas das bandas musicais, a dança acabou suprimida na apresentação de artistas que sempre contavam com a presença de corpo de baile.

${ }^{7}$ Disponível em http://www.ileaiyeoficial.com/bio/bandaiye/ . Acesso em 08/07/2020.
} 


\section{Deusa do ébano e empoderamento da mulher negra}

A Noite da Beleza Negra é um evento anual promovido pelo Ilê Aiyê que nasceu logo após o surgimento do bloco e que tem grande relevância e impacto. Criado em 1979, o evento trata-se de um concurso que acontece 15 dias antes do sábado de carnaval e tem como objetivo escolher a Deusa do Ébano, uma mulher negra que representa o bloco durante o desfile do carnaval e demais eventos no decorrer do ano.

Último evento do bloco antes do carnaval, se constitui num concurso para escolha da sua rainha, a Deusa do Ébano. Busca a valorização do padrão de beleza negra, distinguindo-a de um padrão europeizado. Um dos fatores mais importantes para a seleção das candidatas é a expressividade da dança de origem africana. (FREITAS, 1995, p.66)

As candidatas a Deusa do Ébano não são apenas residentes do bairro da Liberdade e dos arredores de onde se situa o Ilê. Elas provêm dos mais diferentes bairros de Salvador e também de cidades próximas.

A ideia de um concurso de beleza voltado exclusivamente para a mulher negra nasceu da percepção de que os tradicionais concursos de beleza feminina existentes em todo o país priorizavam um padrão de beleza eurocentrado. As negras restavam os concursos de "mulatas" ou musas do carnaval. (MARTINS, 2017, p.107)

Ao reconstruir e revitalizar o conceito de beleza (MERCÊS, 2017), a eleição da Deusa do Ébano configura-se como um marco, junto às outras ações do Ilê, na luta antirracista e de criação de um imaginário estético diferente. As candidatas desfilam ao som dos tambores do Ilê e se expressam a partir da dança, com trajes, adereços, cabelos e maquiagem da estética afro. Trata-se de um concurso que, além de exaltar a beleza e a estética negra, também considera para a escolha da deusa a atitude e discurso com relação a questão da negritude e ao papel da mulher negra na sociedade.

o concurso investia em outras formas de avaliação, considerando como quesitos necessários para a escolha de sua vencedora o tipo de penteado apresentado, a roupa utilizada (confeccionada pela própria candidata), as estamparias do tecido, a graça e desenvoltura na dança afro. O próprio formulário de inscrição era considerado um primeiro instrumento de avaliação, uma vez que, juntamente com questões costumeiras em todo tipo de formulário, trazia um questionamento as candidatas: "para você o que é a negritude?" (MARTINS, 2017, p.108) 
O corpo, através da dança e da estética afro, é o caminho através do qual as candidatas revelam seu pertencimento e firmam sua presença no mundo. (OLIVEIRA, 2014). As candidatas realizam sua "evolução" na passarela ao som da Banda Aiyê e desfilam dançando.

O Corpo pode aplicar diferentes ritmos para diferentes movimentos evoluindo de maneira integral, podendo a cabeça e as mãos executarem movimentos vibratórios e ao mesmo tempo circulares, enquanto a pélvis contrai, dobrando os ritmos e os pés marcando o metro do tempo. O pilar policentrismo pode ser facilmente observado nestes corpos executando o samba Ijexá e o samba reggae, os quais se locomovem no espaço de maneira expandida estimulados pelos toques das percussões. (OLIVEIRA, 2020,p.38)

É importante salientar que nesse contexto a dança revela-se também como uma forma de resistência. A dimensão política e social é, portanto, indissociável da presença e ação corporal no mundo.

Dançamos a resistência de um corpo que, ao evocar as mulheres ancestrais por meio dos movimentos, inaugura uma outra coreografia que inscreve dimensões políticas, social e de autoconhecimento, fortalecendo a identidade e reconhecimento de um outro corpo de mulher negra, estabelecendo um vínculo com outras mulheres que como eu tornam-se multiplicadoras de vida para a resistência e para a luta contra o que é determinado pelo colonizador. (OLIVEIRA, 2016, p.171)

A Deusa escolhida na Noite da Beleza Negra assume muitas responsabilidades. Antes do carnaval ela passa uma semana no terreiro de candomblé onde é preparada no sentido espiritual e em termos mais gerais através de exames médicos e controle da alimentação. (FREITAS, 1995)

Quando eleita, esta 'jovem deusa' reina no bloco passando, assim, a receber uma série de orientações espirituais, emocionais e tarefas pedagógicas como, por exemplo, não usar drogas e nem tampouco usar a violência, ministrar palestras sobre as culturas afro-brasileiras, entre outras atividades. Além disso, a Deusa do Ébano irá representar o bloco nos espetáculos, nas apresentações públicas, nos encontros e viagens pelo país e no exterior. (OLIVEIRA, 2017, p. 98)

Todo o processo de preparação e participação do concurso faz emergir, segundo Oliveira (2016) e Oliveira (2017), transformações nas mulheres relativas a auto estima, conhecimentos e pertencimento. Essas transformações, no entanto, transbordam para a comunidade e para aqueles que participam desse processo.

O corpo negro, na proposta do Ilê Aiyê, ao contrário de simplesmente ser erotizado é sensualizado de forma altiva e graciosa por aquelas moças e rapazes que entendem o significado de ser os mais belos dos belos a partir dos embasamentos da Noite da Beleza Negra como momento de retomada aos elementos da sensualidade matricial presentes nos arquétipos de Oxum enquanto geradores psicossomáticos dos elementos de consciência, fertilidade beleza e, liberdade. (SILVA CAC, 2008, p.105) 
É possível afirmar que, no concurso e na atuação da Deusa durante o ano, o corpo da mulher negra abre possibilidades de existência. Tais possibilidades não se dão de forma individual, mas em constantes articulações e relações. A luta empreendida no cotidiano é uma luta de um coletivo. A ação em rede das mulheres negras e sua articulação como coletivo, é capaz de promover transformações amplas na sociedade, uma vez que inspira os mais novos e faz da possibilidade de se tornar deusa um projeto de vida para as crianças e jovens.

Utilizo, para iniciar esse relato, uma das frases que repito quando da referência ao Bloco e que, sem dúvida, constitui um resumo da minha relação com "o mais belo dos belos", o Ilê Aiyê: "Sinto-me feliz por ter crescido querendo ser a deusa do Ébano e não uma paquita da Xuxa". Assumo ainda que, assim como muitas crianças, em um dado momento, almejei ser uma dessas garotas loiras, de olhos azuis e magras, mas percebi que, para ser uma delas, eu teria que ser diferente de quem eu era. Sabemos que isso machuca, dói, exclui e nos torna mulheres invisíveis por não termos uma representatividade nas grandes mídias, nas capas de revistas, nas bonecas infantis, nas propagandas de produtos comerciais. (SANTANA, 2018, p.19)

A dança desses e nesses corpos possibilita, nesse processo, formas de reconexões com a ancestralidade. A dança praticada no concurso da Deusa do Ébano, e a partir delas, faz emergir possibilidades de acesso a história despedaças no translado atlântico, de (re) construção de vínculos sociais e de invenção de outras formas de relação com o mundo. Em diálogo com Simas e Rufino (2018), a dança praticada como rito carregaria em si as perspectivas da ancestralidade e do encantamento.

Os nossos gestos, posturas e olhares transgridem, afirmam e resistem ao tempo. Se para as danças, o corpo é o principal comunicador, então, nossos corpos expressam o poder, a identidade, linguagem e a reflexão sobre as culturas, valores, religiosidade, heranças do legado africano no Brasil. Nossos movimentos corporais criam e recriam estas danças a partir das influências dos elementos das culturas africanas (religiosidade, estética, ideologias), cumprindo um trajeto de afirmação de identidade e reconstrução de identidade social, distorcidas pela colonização, sendo a Dança, a representação ética e estética que contraria a visão da cultura ocidental que desconsidera a integridade humana. Sendo sempre reelaboradas e identificando a reelaboração do conhecimento mítico. (OLIVEIRA, 2016, p.165 e 166)

O corpo que tece articulações a partir de sua presença que re-existe é o corpo que age na transformação das relações sociais opressoras. A potência dos corpos é assumida teoricamente, mas também epistemologicamente e politicamente. "Os corpos são corpos performativos e assim, através do que fazem, renegociam e ampliam ou subvertem a realidade existente". (SANTOS, 2019, p.138). Como nos provoca a filósofa ativista do movimento negro Angela Davis: "Quando a mulher negra se movimenta, toda a estrutura da sociedade se 
movimenta com ela, porque tudo é desestabilizado a partir da base da pirâmide social onde se encontram as mulheres negras, muda-se a base do capitalismo"8.

Movimento cotidiano que flui no corpo como dança. Tomando, nesse sentido, um diálogo mais específico com as danças afro, danças que a partir da sua potência estética e poética revelam formas africanizadas de escrita de si. (SILVA e SANTOS, 2017). Importante salientar que ao adotar plurais para me remeter a origem e diálogo com o continente africano danças afro/ formas africanizadas - busca-se escapar de homogeneizações ainda presentes nos discursos e imaginários brasileiros.

Para além da evidência revelada pela Noite da Beleza Negra, o Ilê Aiyê parece operar de várias formas para a valorização do lugar da mulher e a construção cotidiana de um modo de ser mulher, que carrega e manifesta a sua ancestralidade e as possibilidades de mudança em seus corpos. A dança produzida nesse lugar e a partir dele, a relação com o candomblé ${ }^{9}$, as práticas educativas (que têm as mulheres à frente), o desfile do carnaval (produzido e realizado, em grande parte, por mulheres) indicam que o Bloco Afro Ilê Aiyê é um tempo/espaço de possibilidades de constituição de lógicas de existências que contrapõe opressões que cruzam as questões raciais e de gênero.

\section{Considerações finais}

Percorrer a história de constituição do Bloco Afro Ilê Aiyê sob a ótica de trabalhos acadêmicos que já o tematizaram a partir de diferentes olhares revelou que as características do bloco, suas práticas cotidianas de produção, divulgação, compartilhamento e fortalecimento da cultura afro-brasileira e, especialmente, de empoderamento da mulher negra, apresentam-se como tempos/espaços de ações de luta antirracista. Além disso, geram impactos na comunidade em que o bloco está inserido e, de forma mais ampliada, nacionalmente, uma vez que o Ilê Aiyê influenciou e influencia diversas ações antirracistas no país.

O Ilê Aiyê inaugura, a partir principalmente de sua estética, uma forma diferenciada de luta antirracista ao levar para as ruas do carnaval de Salvador fortes referências africanas que

\footnotetext{
${ }^{8}$ Em artigo do El Pais disponível em https://brasil.elpais.com/brasil/2017/07/27/politica/1501114503 610956.html Acesso em 24/05/2020.

${ }^{9}$ Como afirma Oliveira (2016, p.79), “As religiões afrobrasileiras são na sua grande maioria regidas por mulheres. São as Yalorixas, as matriarcas e protetoras do fundamentos dos Terreiros de Candomblés, Umbandas, etc. que vêm ao longo da história sendo perseguidas pela intolerância religiosa e a demonização dos cultos afrobrasileiros que são práticas dos passado, lembremos da passagem da "arvore do esquecimento" e ainda persiste na atualidade deixando ao longo de sua existências muitas vítimas.
} 
impactam subjetividades e (re) constroem o orgulho de ser negro. Os símbolos, cores, temas, movimentos e sons que o bloco coloca nas ruas transborda resistência e faz emergir aprendizagens por parte daqueles que participam diretamente, mas também das pessoas que assistem e se deslumbram com o espetáculo.

No cotidiano, o Ilê Aiyê também firma sua ação política de construção de uma sociedade mais igualitária e justa. O bloco consolida suas ações para além do carnaval especialmente em suas práticas educativas. A Escola Mãe Hilda, instituição de ensino fundamental; o Band’erê, projeto que oferece formação artística baseada na cultura negra no contra turno escolar e a Escola Profissionalizante, que oferece cursos de capacitação para jovens são ações cotidianas que, ao longo da história do Ilê, fizeram com que se consolidasse como uma Associação Cultural referência no Brasil.

A eleição da Deusa do Ébano na Noite da Beleza Negra é também uma importante ação do bloco. Ao colocar em evidência a mulher, sua beleza e sua forma de estar no mundo, o Ilê demarca um lugar na luta antipatriarcal em articulação com a luta antirracista. Todo o processo de preparação e participação do concurso tem importante papel na mudança das mulheres em relação a auto estima, conhecimentos sobre a cultura negra e pertencimento à comunidade. Essas transformações além de impactarem diretamente as participantes, transbordam e exercem influência na comunidade e nos diferentes lugares em que essas mulheres circulam e passam a atuar mais fortemente.

O corpo que a partir da dança abre possibilidades de existência está, também, em constantes articulações e relações. A luta cotidiana empreendida é uma luta eminentemente coletiva. A ação em rede das mulheres negras, a articulação como coletivo e que, além disso, é capaz de promover transformações amplas na sociedade. Essa instituição é um espaço que desenvolve importantes ações antirracistas e antipatriarcais, suas práticas se desdobram em um outro modo de ser da mulher negra em relação ao status quo das mazelas vividas por elas no Brasil e, articulado a isso, o corpo que ali emerge é tomado como lócus central de produção de linguagem.

Essa pesquisa inicial aponta, portanto, um caminho para aprofundamentos na história da constituição do Bloco Afro Ilê Aiyê e demonstra a necessidade de estudos que se debrucem mais detidamente sobre o papel social que essa instituição desempenha. Para além da revisão de literatura já proposta nesse texto, outras fontes podem revelar importantes aspectos desse bloco tão importante no cenário artístico e cultural brasileiro.

\section{Referências bibliográficas}


ALMEIDA, Armando. A contracultura e a política que o Ilê Aiyê inaugura: relações de poder na contemporaneidade. 2010. 178 f. Tese (Doutorado) - Programa Multidisciplinar em Cultura e Sociedade, Faculdade de Comunicação, Universidade Federal da Bahia, UFBA, Salvador, 2010.

ARAUJO, Gustavo Reis de. Cultura e política na cidade do Salvador : o bloco afro Ilê Aiyê e suas dinâmicas internas e externas. 2020. 174 f. Dissertação (mestrado) - Universidade Estadual de Campinas, Instituto de Filosofia e Ciências Humanas, Unicamp, Campinas, 2020. CAMAFEU, Paulinho. Que Bloco é Esse, Ilê Aiyê, 25 anos, Salvador, Natasha Records, 289.133, 1999.

FERREIRA, Sônia Lúcia Bahia. Comunidades: redutos de identidades culturais narrativas e práticas afirmativas. 2009. $287 \mathrm{f}$. Tese (Doutorado) - Programa de Pós-Graduação em Psicologia Social, Universidade Estadual do Rio de Janeiro, UERJ, Rio de Janeiro, 2009

FREITAS, Joseania Miranda. Museu do Bloco Afro Ilê Aiyê: um espaço de memória e etnocidade. 1995. 105 f. Dissertação (mestrado). Universidade Federal da Bahia, Faculdade de Educação, Salvador, 1995.

MARTINS, Daniel Gouveia de Mello. Minha carne não é só de carnaval, por outra abordagem teórica sobre a atuação dos blocos afro em Salvador (Ilê Aiyê, Malê Debalê e Olodum). 2017. 370 f. Tese (Doutorado). Universidade Estadual de Campinas, Instituto de Filosofia e Ciências Humanas. Campinas, 2017

MERCÊS, Geander Barbosa das. De Ilê Ifé ao Ilê Aiyê: uma releitura do carnaval soteropolitano. 2017. 128 f. Dissertação (Mestrado em Ciências Sociais) - Universidade Estadual Paulista "Júlio de Mesquita Filho", Faculdade de Ciências e Letras . Araraquara, 2017 MOREIRA, Anália de Jesus. As concepções de corpo na associação bloco carnavalesco Ilê Aiyê: um estudo a partir da história do bloco e das práticas pedagógicas das escolas Banda Erê e Mãe Hilda. 2013. 135 f. Tese (Doutorado) - Programa de Pós-Graduação em Educação, Universidade Federal da Bahia, UFBA, Salvador, 2013

OLIVEIRA, Nadir Nóbrega. Sou negona, sim senhora!: um olhar nas práticas espetaculares blocos afro IlÊE Aiyê, Olodum, Malê Debalê e Bankoma no carnaval soteropolitano. Maceió: Grafmarques, 2017. 210p.

OLIVEIRA, Nadir Nóbrega. Deusa do Ébano: um gestual herdado das Danças Afro brasileiras. Diálogos Possíveis, Salvador: Faculdade Social da Bahia, 2014. Disponível em $:<$ http://www.faculdadesocial.edu.br/revistas/index.php/dialogospossiveis/article/viewFile/12 $1 / 84>$.

OLIVEIRA, Nadir Nóbrega. O Corpo e a dança negra no cenário artístico soteropolitano. Revista Ensaios, Salvador. 1994

OLIVEIRA, Nadir Nóbrega. Uma revisão estética negra dos Blocos Afro de carnaval bahiano Ilê Aiyê, Olodum, Malê Debalê e Bankoma. Rascunhos. Uberlândia, MG. v.7 n.1 p. 30-43 jan. jun. 2020

OLIVEIRA, Vânia Silva. ARA-ITÁN: a dança de uma rainha, de um carnaval e de uma mulher. 2016. 182 f. Dissertação (Mestrado) - Programa de Pós-Graduação em Dança, Escola de Dança, Universidade Federal da Bahia, UFBA, Salvador, 2016.

RISÉRIO, Antônio. Carnaval: as cores da mudança. Afroasia. N.16, 1995, p.90-105. Disponível em https://portalseer.ufba.br/index.php/afroasia/article/view/20848. Acesso em $\underline{28 / 06 / 2020}$

SANTANA, Daniele Santos. Ilê Aiyê: Interações entre arte, educação e cultura afrobrasileira. 2018. 162 p. Dissertação (Mestrado - Mestrado em Artes) -- Universidade de Brasília, 2018.

SANTOS, Boaventura de Souza. O fim do império cognitivo: A afirmação das epistemologias do Sul. Belo Horizonte: Autêntica, 2019. 
SIMAS, Luiz Antonio e RUFINO, Luiz. Flecha no tempo. Rio de Janeiro: Mórula, 2019.

SIMAS, Luiz Antonio e RUFINO, Luiz. Fogo no mato: A ciência encantada das macumbas. Rio de Janeiro: Mórula, 2018.

SILVA, Luciana e SANTOS, Inaycira Falcão. Colonialidade na dança e as formas africanizadas de escrita de si: perspectivas sul-sul através da técnica Germaine Acogny. Concept., Campinas, SP, v. 6, n. 2, p. 162-173, jul./dez. 2017

SILVA, Carlos Ailton da Conceição. Os belos, o trânsito e a fronteira. Um estudo sócioantropológico sobre o discurso auto-referente do Ilê Aiyê. 2008. 131 fls. Dissertação (mestrado) - Universidade Federal da Bahia, Faculdade de Filosofia e Ciências Humanas. Programa de Pós-Graduação em Estudos Étnicos e Africanos, 2008.

SILVA, Fracisco Carlos Cardoso da. Invenções Negras na Bahia: pontos para discussão sobre o Racismo à brasileira. 2008. 233 f. Tese (Doutorado) - Programa de Pós-Graduação em Ciências Socias da Pontifícia Universidade Católica de São Paulo, PUC-SP, São Paulo, 2008.

SILVA, Fracisco Carlos Cardoso da. Construção e Des construção de identidade racial em Salvador: MNU e Ilê Aiyê no combate ao Racismo. 2001. 174 f. Dissertação (Mestrado) Mestrado em Sociologia da Universidade Federal da Paraíba. Campina Grande, 2001.

SOUZA, Jovina C. "Ilê Aiyê, que bloco é esse?": Respostas a Paulinho Camafeu. 2007. 128f. Dissertação (Mestrado). Programa de Pós-graduação em Letras e Lingüística da Universidade Federal da Bahia. Salvador, 2007. 